\title{
The Analysis of the Development of Sharing Economy in the Internet Era
}

\author{
Yajing Sun \\ Beijing Jiaotong University, Beijing 100044, China \\ yjsun1993@163.com
}

Key words: sharing economy; Internet; interactive mechanism

Abstract. Sharing economy based on Internet technology is in a state of rapid advance, and is unobtrusively changing people's lifestyle. By exploring the new economic properties of Internet, the paper analyzed the interactive mechanism between sharing economy and Internet. Then discussed the challenges that Internet brings and put forward some suggestions on how to make breakthrough.

\section{Introduction}

"Sharing economy" was voted to one of the top ten concepts changing the world by Time in 2011. Along with high speed development of Internet technology, especially the mobile Internet technology, sharing economy has reached a peak. Well-known rapidly developing sharing platforms like Airbnb、Uber、 Lyft lead the world in sharing economy. In China, "Internet +" plan was put forward by the prime minister Keqiang $\mathrm{Li}$ for the first time in his government work report in 2015. The plan is trying to create new economic growth areas by promoting the mobile Internet, cloud computing, big data, combined with modern manufacturing industries. The National Development and Reform Commission also emphasized to form a new pattern of economy on the basis of the Internet and develop the sharing economy. In the era of the Internet, sharing economy is overthrowing the existing business models and reconstructing the business relationship. The development of sharing economy is of great importance to improve economic efficiency and unleash the dynamism of economy.

At present, most scholars analyze the reason of sharing economy boom, its nature, effects, development predicament and direction using the method of case analysis and theoretical analysis. Yongbiao Zheng, Dan Wang (2015) analyzed its impacts on the society, economy and people's lifestyle, explored its dilemma and put forward some suggestions of promoting its development healthily and orderly by exploring the reasons and the natures of the sharing economy. ${ }^{1}$ Jingyu Yan (2015) studied Uber's development and what changes sharing economy like Uber brings to macroeconomy, society and people's lifestyle, then provided advices to promote sharing economy development. $^{2}$ In terms of the role of the Internet to sharing economy, scholars generally agreed that the Internet technology greatly reduces the information asymmetry between the micro participants which significantly lowers the search, negotiation, supervision and other aspects of transaction costs caused by asymmetric information. But there are some drawbacks in indepth analysis of the mechanism of the Internet to sharing economy development.

This paper innovatively studies the interactive mechanism between Internet and sharing economy on the basis of Internet's new economic characteristics, the challenges for the sharing economy in the Internet age and tries to find out how to make sharing economy lead to economic growth.

\section{The interactive mechanism between the Internet and sharing economy}

As a new economic form, sharing economy is experiencing from platforms sharing to users sharing and to the products (or service) sharing. Sharing economy as it is known today refers to the sharing of products and services in the age of the Internet. It is essentially a lease economic model on the Internet whose essence is the temporary transfer of the right to use. It's realized by deals of individual rights to use of the idle resources on the Internet third-party platforms. Before the advent of Internet, idle resources' random supply and demand information was hard to match fast which caused 
very high transaction costs. Once the lease transaction costs are more than the purchase transaction costs, consumers' rational choice is to buy rather than rent. And the emergence of the Internet greatly reduced the search, negotiation, supervision and other aspects of the transaction costs caused by asymmetric information which led to sharing economy rising rapidly.

\subsection{Internet's new economic characteristics}

1.1.1 Intelligent connectivity. The core of the Internet is the transmission of information, and its intelligent connectivity can reduce the replication of information products and transmission cost to almost zero, its technical features make digital information products copied and transmitted simultaneously. ${ }^{3}$ Connectivity enables Internet users to copy and receive information products after finding information sources. The more users are connected, the more times information products can be copied and transmitted, which greatly reduces the average cost and achieve the supply-side economies of scale. On the other hand, the more Internet information sources are, the more information channel the recipients can establish, the more available information can be used, and the greater the effects of network to information recipients are. On the contrary, more recipients also lead to greater effects of the Internet, thus forms a positive feedback. And due to the intelligent network can effectively reduce the information search costs caused by increasing information sources and recipients, which can increase the customer's utility and form the demand-side economies of scale.

1.1.2 Intelligent interactivity. Intelligent interactivity refers to as the main body of economic activities----people or companies, don't have to response in real time themselves, and they can use the intelligent means of communication. For instance, Dell established the selection board on their website to communicate with their customers to obtain demand information, which can automatically convert customer demand information to production parameters. ${ }^{4}$ The intelligent interactivity reduces the information communication cost which can be huge.

\subsection{The interactive mechanism between the Internet and sharing economy}

1.2.1 The Internet can greatly reduce the transaction cost and make leasehold mode as mainstream possible. In fact, sharing economy in essence is still a kind of institutional arrangement of property rights and contracts, is a leasing contract model. Although renting and buying both have its own search costs of tenants and buyers, the lease contract just rent the right to use for a period of time, rather than buyout the right to use the assets. In order to prevent improper using and depreciated assets after rental, the terms and conditions of a lease contract shall be to maintain the interests of both contract parties and rental additional regulatory costs are involved. When the transaction costs of leasing agreements are more than the sale and purchase contracts, sharing economy can only be academic.

And the intelligent connectivity of the Internet can improve the efficiency of signal transmission and information screening, making information production and propagation more instant, convenient and sensitive, which solves the problem of asymmetric information. Furthermore, matching, verification, communication, payment, comments, and other functions online greatly reduce the search, supervision costs and such high costs of transaction, that provide for the development of sharing economy. Consumers don't have to buy goods in order to meet the demand for "use". They can pay only a small amount of cost of leasing in a sharing economy era.

1.2.2 The Internet establishes the credit mechanism. Sharing economy is an economic model which is highly dependent on credit. With no credit, it is hard to imagine that a consumer can safely take a stranger's car or live in a stranger's home. Before the advent of the Internet, leasing transaction was just a one-off game, which made it difficult to feed traders' credit back to other participants. But now various evaluation systems of the Internet platform based on the technology of cloud computing and big data and so on can fully expose the participants' credit, inspiring the ascension of overall credit level.

What's more, Internet cluster social intercourse can make strangers communicate and exchange through social networks online (WeChat, Weibo, BBS, etc.). This intelligent interactivity makes every ordinary consumer convenient to observe potential suppliers' credit, and helps them make a rational choice. 
1.2.3 The integration of Internet and sharing economy expands the development fields. Information products' essence is virtual, which means it needs the help of a specific industry to achieve the development of Internet industry. The convergence of sharing economy and the Internet is to implant the Internet thinking into the urban transportation, logistics transportation, lodging and other aspects, leading various industries to tend to be more convenient and intelligent. At the same time, the integration also expands the development area and enrich the forms of the Internet industry. With sharing economy bringing more new business models, the demands for information solutions of small and medium-sized enterprises will greatly increase. In the future, Internet industry's main function, providing software support, will transform to create value for companies. One of the most core functions is to help enterprises to improve competitiveness through the analysis and using huge amounts of data. ${ }^{5}$

\section{The challenge for the sharing economy development}

2.1 Big data can become industry barrier. Sharing economy highly depends on big data to matching supply and demand information timely in order to reduce the information asymmetry and lower transaction costs. Enterprises engaged in sharing economy generally require a lot of the early investment obtain the initial data, but according to the Metcalfe's law of information network expansion effect, the value of the network is equal to the square of the number of nodes, which means network benefits grow exponentially with the growth of the Internet users. Secondly, the intelligent connectivity of the Internet determines that the acquisition, processing, storage and use of big data have obvious scale economy. That means accompanied by the number of participants increasing and participants being connected broader, production cost per unit data will decline at a faster speed, and data quality will improve faster.

This characteristic of the Internet determines the competitiveness of the sharing economy incumbents will benefit from the growing scale effect and network effect of big data. Eventually they will have constant monopoly with the advantage of self-reinforcing big data which is difficult to overcome in the short time only on money.

2.2 The honesty and trust problem of the Internet. Trust is the most efficient approach to reduce transaction costs. Sharing economy joint the suppliers and demanders of services or assets, which is likely to involve the personal and property safety, and that is the most controversial part of sharing economy pioneers Uber and Airbnb. Although the Internet has set up a credit mechanism, its effectiveness is still questioned.

The honesty and trust problem of Internet is usually solved by social network evaluation mechanism. The pioneers of sharing economy successfully launch their own products and services by fully implementing the Internet brought forth by modern technology under the premise of more and more communication channels, and realize information sharing with social media, APP and some comments. In addition, social network evaluation can't solve the personal and property security problem of the suppliers. Sharing economy's short-term lease mode determines it tend to be onetime deal for the buyer, therefore the seller's assets are easy to damage, and this moral hazard is often unable to avoid. So the Internet trustworthiness problem is still eager to be solved.

2.3 Sharing economy's "altruism” thinking makes customer experience more important.From Adam Smith's "selfish" thinking, sharing economy’s “altruism” thinking gradually developed. Adam Smith thought that the motive of economic activity is to be "selfish", and he said "letting people pursue their own interests, can promote the interests of the whole community". On the contrary, sharing economy values platforms and transaction costs and emphasizes "altruism" thinking, providing convenience for both parties. In Internet era, new information, applications will appear almost every day, so if you do not attach great importance to user's idea, they're likely to abandon your product immediately when they encounter trouble using your service, and users are hard to regain once lost, which makes letting users experience than expected particularly important. In this condition, designing and producing are both on thin ice.

2.4 "Internet + industry" gives rise to new network ecology. Different from the traditional digital economy, sharing economy emphasizes on network ecology. For example, bank plus the Internet is 
a bank that have online banking service, but the Internet plus bank is equal to a network ecosystem with digital financial services, like Betterment and Wealthfront. One of the main difference is that online banks uses the Internet as a tool, but Betterment thinks itself as a tool used by Internet. Under the background of "Internet +" strategy and the implementation of the concept of sharing development, the integration of Internet and industry will create more new network ecology and innovative enterprises. Sharing economy will welcome the unknown challenges.

\section{How to break through}

3.1 Open data. The technical characteristics of the Internet may make big data become oneof the important industry barriers, and open data will lower the entry barriers to keep the market in a state of effective competition. In the past, data information is the soul assets of an enterprise belonging to the commercial secret. In the future, the data is shared, the more people use, the greater the value is. By means of open data, small micro enterprises canenter the market more easily, reverse more traditional industries, and will offer more opportunities of innovation and entrepreneurship. Weather, maps, parking space and so on are common examples. There are, of course, privacy, big data analysis, streams computing and such issues to be solved.

3.2 Improve the mechanism of credit reporting. Brian Chesk, the co-founder and chief executive of Airbnb had mentioned the core of sharing economy is trust. And it's hard to keep checks and balances of the risk of trust only relying on moral and law, which is also the significance of the credit system. Perfect credit system can ground out the unsafe factors of sharing economy, at the same time, the user's default and dishonest acts can also provide important evidence for evaluating individual's credit level in the individual credit systems.

The current social network evaluation credit reporting mechanism tends to protect the demanders of products or services, and has insufficient protection for suppliers. In order to improve the credit mechanism, the enterprises shall establish a two-way credit mechanism to protect the interests of both parties, and to prevent idle resources of high quality squeezed out of the market. In addition, in the future sharing economy transactions won't be deals only between people, but between enterprises. So as to the problem of enterprise's credit, it also needs to work with the traditional credit rating agencies to perfect the credit system.

3.3 Providing the best customer experience. In the age of the Internet, information generates and spreads very quickly. In face of information explosion, consumers' time becomes limited resources, so how to use time pockets, extending the using time and locking future time become the three strategies in new economic era. This requires enterprises to better understand customers' needs, improve the experience, and let the problems solved quickly. In the future, more personalized and intelligent design will become a top priority.

3.4 Continuous innovation. Relying on the Internet, sharing ideas will fuse with more traditional industries, and new business models will emerge in endlessly. Along with improving entrepreneurship environment in our country, entrants are more likely to enter the market, which would require the incumbents to innovate continuously to maintain their monopoly power, otherwise they will certainly be surpassed by latecomers and its monopoly will also cease to exist.

\section{Conclusion}

The integration of Internet and sharing economy is an opportunity as well as a challenge for the development of sharing economy. The intelligent connectivity and intelligent interactivity of the Internet improve the speed of information production and propagation, greatly reduce the transaction costs caused by information asymmetry. And the credit mechanism established on Internet cluster network and big data analysis solves the problem of trust partially, creating the conditions for the development of sharing economy.

On the other hand, in the era of "Internet +", the development of sharing economy is also faced with some challenges. Firstly, the Internet technology represented by big data is likely to become a strong industry barrier, which will cause monopoly and reduce the market efficiency. Secondly, 
one-way network evaluation mechanism is difficult to protect the rights and interests of suppliers effectively. Finally, innovations emerge in endlessly, enterprises will be eliminated quickly if they do not take customers' experience seriously.

Therefore, sharing economy needs to open data to reduce the barriers to entry to seek a breakthrough and cooperate with traditional agencies to improve the credit reporting mechanism. They also needs to understand customers' needs, attach great importance to customers' experience, and innovate continuously to maintain a low cost advantage.

\section{Reference}

[1] Yongbiao Zheng, Dan Wang. The analysis of the development of sharing economy based on mobile Internet [J]. Journal of Beijing Institute of Economic and Management, 2015, 30(2):37.DOI:10.3969/j.issn.1008-7222.2015.02.001.

[2] Jingyu Yan. The thinking of Uber enlightening and leading the global sharing economy development [J]. Market Modernization, 2015, (19):13-17.DOI:10.3969/j.issn.10063102.2015.19.011.

[3] Qiang Guo. Business model research of the Internet based on the new economic characteristics [C]. //2006 Annual meeting of China association for science and technology. 2006:497-502.

[4] Slywotzky A J. The age of the choiceboard [J]. Harvard Business Review，2000， 78(1)

[5] "Sharing economy" brings IT industry new opportunities- during the visit to SAP executive vice president Cloth [J]. Science \& Technology for China's Mass Media, 2013, (5):33.

[6] Lijun Yang. Sharing economy in Internet era [J]. Telecom World. 2015, (14):5858.DOI:10.3969/j.issn.1006-4222.2015.14.041.

[7] Yunyun He, Yajie Sun. The limousine service controversy under the theory of sharing economy [J]. Business, 2015, (6):256.

[8] Xiwen Wang. "Internet +" builds information physical sharing economy (CPSE) [J]. Office Automation, 2015, (4):9-11.DOI:10.3969/j.issn.1007-001X(x).2015.04.002. 